CBIE-LACLO 2015

Anais do XXI Workshop de Informática na Escola (WIE 2015)

\title{
Felpo Filva e as TICs: oportunizando práticas contextualizadas de escrita e leitura no terceiro ano do ciclo de alfabetização
}

\author{
Lisandra Almeida da Silva ${ }^{1}$, Silvana Corbellini ${ }^{2}$, \\ ${ }^{1 e} 2$ Universidade Federal do Rio Grande do Sul (UFRGS) \\ Caixa Postal 15.064 - 91.501-970 - Porto Alegre - RS - Brazil \\ lisandra.almeida@hotmail.com, silvanacorbellini@gmail.com
}

\begin{abstract}
This article is an experience report about a work developed from the reading of Eva Furnari's book Felpo Filva, in a third year of elementary school class of a municipal school in Porto Alegre. The work's objectives were to investigate the student's writings describing how they made their productions and how they were motivated facing the challenges and situations created from the reading and the activities experienced with several reading materials in the classroom and in the informatics laboratory. The subjects are 26 children from both genders, with ages that vary from 8 to 11 years-old, in the year of 2014. The results show evolutions regarding the writing levels and reading and literacies practices development.
\end{abstract}

Resumo. Este artigo trata-se de um relato de experiência sobre o trabalho desenvolvido a partir da leitura do livro Felpo Filva, de Eva Furnari, em uma turma de terceiro ano do ensino fundamental de uma escola municipal de Porto Alegre. Os objetivos do trabalho foram investigar as escritas dos alunos descrevendo como realizaram suas produções e como se motivaram diante dos desafios e situações criadas a partir da leitura e das atividades vivenciadas com diversos portadores de texto ${ }^{l}$ na sala de aula e no laboratório de informática. Os sujeitos são 26 crianças de ambos os sexos, com idades que variam de 8 a 11 anos, no ano de 2014. Os resultados mostram evoluções no que se refere aos níveis de escrita e desenvolvimento da leitura em práticas de letramento

\section{Introdução}

Observou-se na prática que as crianças do segundo ano vinham apresentando muitas dificuldades para escrever textos e histórias. Demonstravam-se apáticas e pareciam não ter ideias. Quando solicitadas para escrever sobre algum assunto verbalizavam que era chato e somente faziam com muita insistência da professora. Tornavam-se necessários 
CBIE-LACLO 2015

Anais do XXI Workshop de Informática na Escola (WIE 2015)

outros recursos, tais como a exploração oral sobre o assunto ou imagens para que pudessem construir frases ou pequenos textos.

A escola então, diante deste problema, se mobilizou na busca de um livro que fosse referência de um trabalho mais pontual de leitura e produção de textos. Sendo assim iniciou-se o trabalho com o livro de Eva Furnari e hoje ele constitui-se em um dos pilares de trabalho do terceiro ano de uma escola municipal de ensino fundamental de Porto Alegre/RS. A proposta surgiu para mobilizar as crianças, oportunizando-as experiências de práticas de escrita e leitura contextualizadas juntamente com práticas de letramento, que visam romper com uma produção textual mecânica onde as crianças não utilizam todo seu potencial criativo tampouco relacionam o ato de escrever a sua funcionalidade.

Tal necessidade pedagógica detectada nos terceiros anos entrou em consonância com o que a escola vinha organizando como linha de ação pontualmente frisada em seu Plano Político Pedagógico (PPP) em relação ao letramento. A escola desafiou-se a buscar alternativas que mobilizassem os alunos propondo ações que mudassem significativamente o conteúdo linguístico do que escrevem motivando-os de uma forma que $o$ ato de escrever se tornasse uma ação realmente prazerosa.

Durante as reuniões de planejamento com as professoras e com a coordenadora pedagógica surgiu a ideia de aliar as atividades na sala de aula com o uso das Tecnologias de Informação e Comunicação (TICs), pois elas propiciam espaços qualificados de leitura e escrita através dos seus hipertextos, blog e jogos que, por serem de natureza interativa, mobilizam as crianças possibilitando o desenvolvimento de competências em meio a práticas de letramento que a sociedade moderna exige.

As mais variadas propostas de leitura e escrita alternaram-se entre o espaço da sala de aula e o laboratório de informática como a escrita no blog, exploração dos recursos do Paint, pesquisas na internet e jogos, entre outros, e possibilitaram descrever como as crianças fizeram suas produções e como se motivaram a partir de desafios e situações criadas pelo professor, sendo possível investigar também quais aquelas realizadas na sala de aula e no laboratório de informática que despertaram maior interesse nas crianças.

A relevância do trabalho com o livro Felpo Filva, de Eva Furnari, evidencia-se através da mudança no perfil do aluno demonstrado através da sua evolução nos níveis de escrita e no desenvolvimento da leitura e oralidade, e comprovam mudanças no que se refere a diversificação do trabalho e o rompimento de práticas mecanizadas e descontextualizadas na alfabetização, através das múltiplas atividades vivenciadas pelas crianças.

Sendo assim estabelece-se aqui a necessidade de relatar este trabalho que mobilizou a instituição e que trabalha para qualificar os processos de leitura e escrita dos seus alunos do terceiro ano do ciclo de alfabetização.

\section{O Livro Felpa Filva: proposta de trabalho de hoje}

Este livro é direcionado ao público infantil. O livro conta a história de Felpo Filva, um coelho escritor que vive triste e isolado e que em um determinado momento começa a receber cartas da coelha Charlô. Uma coelha bastante crítica com relação às poesias e aos livros escritos por ele. Felpo Filva entra em crise e passa a se questionar e rever 
CBIE-LACLO 2015

Anais do XXI Workshop de Informática na Escola (WIE 2015)

certas posturas. A história evolui de maneira divertida com trocas de correspondências entre Felpo e Charlô e, nestas trocas, a autora vai inserindo, ao longo do livro, vários tipos de texto, como poema, fábula, carta, manual, receita, lista, entre outros.

Procura-se em cada ano estabelecer um foco para certos portadores de texto.Este ano o trabalho direciona-se para criação de poemas, escrita da autobiografia, pesquisa sobre a autora Eva Furnari, recontagem de contos de fadas preferidos do grupo, criação de manuais de uso de brinquedos e jogos, criação de diálogos entre Felpo e Charlô, composição de muitas listas e bilhetes e as oficinas de brinquedos, de doces e de receitas que utilizam ervas. As propostas dividem-se em dois espaços de trabalho: sala de aula e laboratório de informática. Propõe-se ainda a criação de um blog para as postagens das atividades e possibilitar que alunos acompanhem com a família o trabalho em casa, escrevendo comentários e oportunizando a troca e comunicação entre famíliaescola. A proposta do blog é para uso no espaço escolar, mas também possibilita que as interações ocorram em casa para aqueles que possuem acesso a internet, que são poucos na turma. No laboratório de informática objetiva-se ainda que os alunos aprendam a utilizar o Google, acessar sites, aprender a utilizar o Paint e seus recursos, digitar materiais no Word e jogar em sites que desenvolvam a leitura com temática de algum portador de texto trazido pelo livro e a elaboração de escrita para envio de cartões virtuais.

\section{Definições de Letramento e o uso das TICs}

O trabalho com o livro Felpo Filva e a dinâmica de atividades proposta oportuniza que o aluno acesse a determinados portadores de texto, tais como bilhetes, cartões, bulas de remédio, receitas, manuais de uso, listas, fábulas, contos de fada e poesias. Alguns destes até já fazem parte do seu cotidiano, porém é a sua inserção na prática escolar que leva a uma releitura e direciona a criança a se apropriar destes objetos escritos, de uma forma que pode conduzi-la ao desenvolvimento das suas concepções sobre as funções da escrita, remetendo-a também a pensar sobre o funcionamento da linguagem.

Para Soares (2002, p. 144): "letramento são as práticas sociais de leitura e escrita e os eventos em que essas práticas são postas em ação, bem como as consequências delas sobre a sociedade". Assim, é possível elencarmos práticas e contextos de letramento dentro e fora da escola atuando conforme necessidades e interesses das pessoas e constatar que para cada grupo há diferentes formas de significar e atribuir sentidos para certos eventos de letramento.

Para Kleiman (1995, p. 19), "letramento é um conjunto de práticas sociais que usam a escrita, enquanto sistema simbólico e enquanto tecnologia, em contextos específicos, para objetivos específicos". Desta maneira, parte-se do pressuposto, com os trabalhos sistemáticos na escola com determinados textos, que os sujeitos pensem antecipadamente sobre sua estrutura e organização.

O uso do blog aponta para várias possibilidades, assim como a utilização dos jogos disponíveis na internet. Segundo Santarosa (2010), a palavra blog é resultante da contração entre as palavras web e log (registro) na web (em texto na internet). É um sistema de publicação na web destinado a divulgar informação semelhante a um diário, sendo o seu diferencial a interação entre os internautas e o editor (aquele que cria o blog). 
É preciso permitir qualificadamente o acesso dos meios tecnológicos aos alunos, pois segundo Ferreiro (2006) estar alfabetizado hoje indica alguém que transita com eficiência e sem temor numa intrincada trama de práticas sociais ligadas à escrita, produzindo textos nos suportes que a cultura define como adequados para as diferentes práticas. Interpretar textos de variados graus de dificuldades em virtude de propósitos igualmente variados, buscar e obter diversos tipos de dados em papel ou tela.

\begin{abstract}
Se, por um lado, a escola (e, como parte dela, os professores) frequentemente propõe um modelo de leitura e de escrita linear, por outro, cada vez mais as novas tecnologias apresentam suportes de leitura e de produção coletiva de texto em forma de hipertexto que transformam quem lê e quem escreve em condutor de seus caminhos de leitura/escrita, em capitão de sua própria viagem, em guia também nas navegações dos outros (SOUZA, 2005, p. 4).
\end{abstract}

Sendo assim, em termos de alfabetização e letramento, nos dias de hoje é preciso o investimento e esforço da escola buscando a qualificação necessária em termos humanos (oportunizando formações aos professores) e tecnológicos (investindo em máquinas e softwares) propiciando condições ao aluno de atender as demandas sociais no que se refere ao uso de sua língua materna.

\title{
5. Ações e Construções
}

Expõem-se a seguir algumas das ações que foram desenvolvidas a partir do livro Felpo Filva.

\begin{tabular}{|r|l|l|}
\hline \multicolumn{1}{|c|}{ Atividades } & \multicolumn{1}{c|}{ Objetivos } \\
\hline 2 & Vamos fazer listas? & $\begin{array}{l}\text { Incentivar a pensar elencando assuntos, objetos, ações ou } \\
\text { prioridades que não podemos esquecer ou que devemos seguir. }\end{array}$ \\
\hline 3 & $\begin{array}{l}\text { Construção de } \\
\text { acrósticos }\end{array}$ & $\begin{array}{l}\text { Fomentar a associação de ideias, oportunizar o desenvolvimento do } \\
\text { vocabulário eda criatividade. }\end{array}$ \\
\hline 4 e pesquisa na & $\begin{array}{l}\text { Inseri-los no espaço da internet oportunizando vivenciar conteúdos } \\
\text { em hipertexto com suas possibilidades de coleta e seleção de } \\
\text { informações tornando-os ativos frente aos estímulos dados pelos dos } \\
\text { recursos da internet. }\end{array}$ \\
\hline 5 & $\begin{array}{l}\text { Construção de novos } \\
\text { Pelpos e acrósticos no } \\
\text { Pala de aula e no blog } \\
\text { vários tipos de linhas, formas, aprendendo a selecionar e editar } \\
\text { objetos usando as cores, assim como aprendendo a fazer a escrita na } \\
\text { caixa de texto. }\end{array}$ \\
\hline 6 & $\begin{array}{l}\text { Torná-los leitores e escritores ativos buscando desenvolver estas } \\
\text { duas competências de maneira igual em uma perspectiva } \\
\text { colaborativa. } \\
\text { presenciais e virtuais de } \\
\text { para os professores }\end{array}$ & $\begin{array}{l}\text { Fortalecer o vínculo entre os professores e os alunos estimulando-os } \\
\text { a pessoalizarem a escrita. }\end{array}$ \\
\hline $\begin{array}{l}\text { Jogando com os } \\
\text { portadores }\end{array}$ & $\begin{array}{l}\text { Estimular os alunos a lerem a fim de alcançarem os objetivos do } \\
\text { jogo através do seu conteúdo lúdico e essencialmente interativo. }\end{array}$ \\
\hline
\end{tabular}

\section{Tabela 1: Ações Realizadas com Felpo Filva}

\section{Procedimentos Metodológicos}

Este trabalho é uma proposta da instituição para as turmas do terceiro ano no período de 2014, com objetivos definidos e que surgiu da necessidade de se oportunizar vivências contextualizadas de escrita. Trata-se de um estudo de caso (YIN, 2010) realizado a partir do trabalho efetivado com uma turma do terceiro ano de uma escola municipal. 
CBIE-LACLO 2015

Anais do XXI Workshop de Informática na Escola (WIE 2015)

Os objetivos foram investigar as escritas dos alunos descrevendo como realizaram suas produções e como se motivaram diante dos desafios e atividades propostas em sala de aula e no laboratório de informática. Foram sujeitos da pesquisa 26 alunos de ambos os sexos, com idades entre 8 e 11 anos, no período de agosto a outubro de 2014.

\section{Tempos e Espaços das escritas: análise das atividades}

As crianças mostraram-se muito disponíveis para execução de todas as tarefas que objetivavam produzir um tipo de portador de texto. Para tanto, cada atividade tinha sua sequência didática previamente organizada com previsão de tempo, divisão de tarefas e objetivos claramente definidos.

Possibilitar as mais diversas situações de aprendizagem engajadas no livro Felpo Filva oportunizou as crianças o acesso a certos portadores de texto através de sua leitura e escrita/reescrita e observar seus esquemas interpretativos no que se refere a construção da linguagem. Sendo assim, o que se objetiva no conjunto de ações é favorecer as crianças condições de desenvolvimento da sua comunicação escrita, problematizando-a.

Segundo Ferreiro (2000), a escola deve permitir um acesso inteligente às condições de enunciação próprias da escrita: é preciso aprender a solicitar, argumentar, contar, dar instruções, perguntar, responder, informar, comentar e dialogar por escrito.

Para tanto foram realizadas atividades na sala de aula e no laboratório de informática como a construção de acrósticos, de listas e bilhetes, pesquisa na internet, visitas ao blog e produção de recados e cartões virtuais, que nos permitem inferir sobre os avanços das crianças no que se refere ao seu nível de escrita e leitura assim como sua motivação/envolvimento com o trabalho.

Há um caminho que começou a ser traçado desde a leitura do livro e que foi se construindo e avançando a cada atividade, a cada oportunidade de debate, a cada interação com as TICs. Todas as ações demandaram o envolvimento e participação dos alunos para que pudéssemos dar continuidade ao caminho instituído. Os alunos avançam na trilha dos conhecimentos da linguagem, pois houve uma gama de possibilidades de interação com os objetos e entre os sujeitos que concedeu a turma oportunidade de indagar, inferir e buscar significação para aquilo que estava sendo registrado.

Todas as atividades descritas dentro de uma visão global propiciaram trabalhar com certos portadores sob o contexto do letramento, sendo possível observar o desenvolvimento da aprendizagem das crianças sob dois aspectos, no que se refere à linguagem: o avanço no nível de escrita de algumas crianças, assim como coloca Seber: "Com referência à escrita, o resultado de todo esforço de entendimento resulta na progressão de ideias sobre como expressá-las, e assim elas se tornam verdadeiras usuárias da língua" (SEBER, 1997, p. 237).

No que se refere ao avanço nos níveis de escrita, observa-se que desde o início do trabalho até o momento três crianças evidenciaram avanço do nível silábico para o silábico-alfabético e iniciam processo de leitura, e três alunos avançaram do nível présilábico para o silábico. Temos no grupo quatro crianças em nível silábico-alfabético, sendo que uma já registrava este nível antes do trabalho iniciar e observou-se neste aluno um avanço na leitura que antes parecia bloqueada, mas agora em vias de 
CBIE-LACLO 2015

Anais do XXI Workshop de Informática na Escola (WIE 2015)

efetivamente acontecer, pois se demonstra mais seguro, e mais autônomo no reconhecimento das unidades sonoras.

Na turma com um total de 26 crianças, 17 encontram-se no nível alfabético e duas com necessidades educacionais especiais, que possuem objetivos escolares direcionados à socialização e convivência com os pares, não sendo o foco deste ano a alfabetização.

O avanço nos níveis de escrita de seis crianças indica-nos que o trabalho com o livro de Eva Furnari traz em seu conteúdo o apelo do letramento que as fizeram avançar em seus processos de alfabetização porque foram favorecidos pela interação e vivências que lhes foram propiciadas na sala de aula e seus recursos visuais. Através das oficinas e no uso contínuo das TICs no laboratório de informática, através da pesquisa na internet, o uso frequente do blog na interação com os professores e entre os alunos, através da escrita dos comentários e o acesso aos recursos do próprio computador como Paint, assim como dos jogos educacionais.

O trabalho contínuo no blog mobilizou os processos de alfabetização, pois para Santiago e Lima (2013, p.81) ele constitui-se em uma "[...] ferramenta de aprendizagem colaborativa que além de apresentar inúmeras possibilidades de aprendizagem, trabalha fundamentalmente com a leitura e a escrita, sendo possível elevar o nível e a competência da leitura e escrita dos estudantes [...]". Oportunizou também ao grupo uma troca nunca antes vivenciada. A exposição dos trabalhos da turma na rede mundial de computadores e a comunicação neste espaço motivaram e mobilizaram o grupo a querer mostrar-se e a escrever até mesmo da sua casa. O blog, como ferramenta pedagógica, constituiu-se para este trabalho, como um portfólio virtual de atividades, evidenciando a produção dos alunos em todas as ações desenvolvidas no projeto.

Certas perguntas como: "Vamos escrever manuais de uso"? "Vamos escrever listas"? "Vamos trocar recados"? constituíram-se como comandos que o grupo acolheu e executou sem questionar. Realizar listas de coisas malucas e trocar bilhetes foram propostas acolhidas por todos e realizadas com entusiasmado envolvimento $\mathrm{e}$ participação. Mesmo por aqueles que ainda não escrevem alfabeticamente, mas com ajuda dos colegas também colocaram suas ideias no papel e, avançaram em seus processos de alfabetização, visto que agora há seis crianças que escrevem mais próximo do registro alfabético.

No que se refere aos 17 alunos alfabéticos houve um avanço na construção de suas frases, bem como na qualidade destas no que se refere ao próprio desenvolvimento das ideias. A escrita atualmente aproxima-se da ortográfica verificada através de testagens e ditados, que são feitos desde o início do ano com palavras de sílabas simples e complexas (usando as dificuldades ortográficas), e o chamado autoditado, que se constitui em escrever palavras a partir de imagens visualizadas. $\mathrm{O}$ avanço é observado também nas mais variadas propostas de produção textual. A leitura saiu de um estágio mais silabado e hoje se observa mais fluência e ritmo. Estas mudanças certamente atrelam-se ao acesso aos diversos gêneros vivenciados e tempo para leitura destes que lhes é proporcionado. A turma realiza semanalmente "roda de leituras", onde cada criança escolhe algo para ler ao grupo.

Sob a ótica das atividades trabalhadas descritas neste artigo podemos inferir que tais situações de letramento que foram vivenciadas constituem-se em práticas de leitura, 
CBIE-LACLO 2015

Anais do XXI Workshop de Informática na Escola (WIE 2015)

escrita e oralidade, sendo estas indissociáveis e que evidenciam um conteúdo textual significativo para os alunos.

\section{Conclusões}

O que um grupo de professores novos na escola queria desde o princípio, como foi descrito anteriormente, era dar um contexto de escrita aos alunos, pois, havia sido identificada a necessidade de um trabalho mais consistente em relação à apropriação do sistema de escrita alfabética, compreensão de convenções ortográficas, leitura e interpretação.

Hoje este trabalho é uma realidade que tem resultados concretos, no que se refere à apropriação e desenvolvimento do sistema de escrita alfabética por parte dos alunos do terceiro ano. Cabe ressaltar que o uso das TICs, tornou o projeto ainda mais desafiador, oportunizaram o desenvolvimento de habilidades em um trabalho visomotor e através do apelo lúdico, em especial dos jogos educacionais que "contribuem para determinar o modo de percepção e aprendizado pelo qual o sujeito conhece o objeto" (SILVA et al., 2013, p. 131). As tecnologias possuem uma gama de recursos que potencializaram a aprendizagem e contemplaram a diversidade de conhecimentos e saberes em turma tão heterogênea como a descrita neste relato.

Podemos assim inferir que as TICs contribuíram para que se alcançasse os resultados obtidos no que se refere a participação e envolvimento dos alunos, e os avanços nos níveis de escrita e fluência na leitura.

Estes resultados evidenciam-se no cotidiano da sala de aula, nas mudanças do perfil do aluno verificado, não somente através dos números citados anteriormente no que se refere aos avanços nos níveis de escrita e no desenvolvimento da leitura e oralidade, mas também pela mudança de postura da escola, equipe pedagógica e corpo docente, com relação a uma proposta de diversificação do trabalho e o rompimento de práticas mecanizadas e descontextualizadas na alfabetização.

Verifica-se um investimento da escola, pois atualmente há mais horas para planejamento e discussões do trabalho, que asseguram a continuidade e a qualidade, pois há dedicação e foco no estudo dos níveis de alfabetização, assim como nas possibilidades de intervenções. $\mathrm{O}$ grupo de professores hoje se fundamenta em estudos de Piaget, no que se refere ao desenvolvimento infantil e baseia-se nas pesquisas de Emilia Ferreiro, que estabelece que a alfabetização é um processo e necessita de intervenção e muitas interações das crianças com o objeto do conhecimento, no caso a linguagem. E assim compreende que a alfabetização "é um produto de uma construção mental da humanidade, a partir de uma tomada de consciência das propriedades da linguagem" (Ferreiro, 2000, p. 62).

A importância do trabalho com o livro Felpo Filva, de Eva Furnari, e seus portadores de texto se reflete através do conjunto das ações vivenciadas que permitiram a interação das crianças com uma variedade de portadores de texto em múltiplas atividades, a fim de que compreendessem a natureza fonética da língua materna ao mesmo tempo em que puderam significar os eventos de escrita e leitura como uma prática social. 
CBIE-LACLO 2015

Anais do XXI Workshop de Informática na Escola (WIE 2015)

\section{Referências}

BRASIL. MEC. Pró-Letramento: Programa de Formação Continuada de Professores dos Anos/Séries Iniciais do Ensino Fundamental - Alfabetização e Linguagem. Brasília: MEC, 2007.

FERREIRO, E. O momento atual é interessante porque põe a escola em crise. Entrevista concedida pela psicolinguísta argentina Emilia Ferreiro a revista Nova Escola. Out. 2006. Disponível em: http://revistaescola.abril.com.br/linguaportuguesa/alfabetizacao-inicial/momento-atual-423395.shtml. Acesso em: 27 out. 2014.

FERREIRO, E. Reflexões sobre alfabetização. Trad. Horácio Gonzales. 25. Ed. São Paulo: Cortez, 2000. (Coleções Questões da Nossa Época, v. 14).

FERREIRO, E.; TEBEROSKY, A. Psicogênese da língua escrita. Trad. D. M. Lichtenstein, L. Di Marco e M. Corso. Porto Alegre: Artes Médicas, 1999.

KLEIMAN, A. B. Modelos de letramento e as práticas de alfabetização na escola. In: KLEIMAN, A. B. (Org.). Os significados do letramento: uma nova perspectiva sobre a prática social da escrita. Campinas: Mercado de Letras, 1995.

SANTAROSA, L. M. C. (Org.). Tecnologias digitais acessíveis. Porto Alegre: JSM Comunicação Ltda., 2010.

SANTIAGO, M. F. e LIMA, R, W. Blog: uma ferramenta de aprendizagem no Ensino Médio Inovador. In: II Congresso Brasileiro de Informática na Educação (CBIE 2013) XIX Workshop de Informática na Escola (WIE 2013), Anais do WIE 2013, p. 80-89. Disponível em: http://www.brie.org/pub/index.php/wie/article/view/2621/2276

SEBER, M. da G. A escrita infantil: o caminho da construção. São Paulo: Scipione, 1997. (Coleção Pensamento e Ação no Magistério).

SILVA NETO, S.; SANTOS, H. R.; SOUZA, A. A.; SANTOS, W. O. Jogos Educacionais como Ferramenta de Auxílio em Sala de Aula. In: II Congresso Brasileiro de Informática na Educação (CBIE 2013) XIX Workshop de Informática na Escola (WIE 2013), Anais do WIE 2013, p. 130-139. Disponível em: http://www.br-ie.org/pub/index.php/wie/article/view/2634/2288

SOARES, M. Novas práticas de leitura e escrita: letramento na cibercultura. Educ. Soc., Campinas, v. 23, n. 81, p. 143-160, dez. 2002. Disponível em: http://www.scielo.br/pdf/es/v23n81/13935. Acesso em: 5 set. 2014.

SOUZA, G. de. Ferramentas disponíveis na web que desafiam o desenvolvimento da comunicação. Do mar das ideias ao mar das letras: algumas navegações sobre a leitura e a escrita. In: BRASIL. MEC/TV ESCOLA. Novas formas de aprender: comunidades de aprendizagem. Boletim 15. Ago. 2005.

YIN, R. Estudo de caso: planejamento e método. $4^{\circ}$ Ed. Porto Alegre: Bookman, 2010. 